\title{
BAG3 protein controls B-chronic lymphocytic leukaemia cell apoptosis
}

\author{
Cell Death and Differentiation (2003) 10, 383-385. doi: 10.1038/sj.cdd.4401167
}

Dear Editor,

B-cell chronic lymphocytic leukaemia (B-CLL), the most common form of leukaemia in North America and Europe, is caused primarily by defective apoptosis. ${ }^{1,2}$ Such defect prolongs the physiological lifespan of the cells and renders them resistant to the effects of therapy. ${ }^{1,2}$ Advanced research on B-CLL pathogenesis and therapy therefore points to the identification of molecules that sustain cell survival and/or contrast death in this form of leukaemia. ${ }^{1,2}$ The expression of a number of antiapoptotic proteins has been detected in $\mathrm{B}$ CLL cells. ${ }^{3-6}$ These include Bcl-2, ${ }^{3-6} \mathrm{Mcl}-1,{ }^{4-6}$ inhibitor of apoptosis proteins (IAPs) $)^{5,6}$ and the cochaperone family member BAG1. ${ }^{4,5}$ Furthermore, surface structures, such as CD40, can transduce NF- $\kappa$ B-mediated survival signals in BCLL cells. ${ }^{7}$ Although all these molecules exert antiapoptotic activities, they do not completely account for the sustained leukaemic cell survival, to which other pathways are likely to contribute. ${ }^{1,2}$

The evidence that BAG proteins, like BAG1, can have a role in $B-C L L$ biology ${ }^{4,5}$ is intriguing. Indeed, proteins that share the BAG (Bcl-2-Associated Athanogene) domain are characterised by their property of biochemically and functionally interacting with a variety of partners, including heat shock proteins (Hsp), steroid hormone receptors, Bcl-2, Raf- $1,{ }^{8}$ involved in modulating the proliferation/death balance. In this respect, they can potentially counteract proapoptotic inputs from more than one side, constituting a versatile tool for contrasting death signals of intracellular, environmental or therapeutic origin. Among BAG family members there is BAG3, also known as CAIR-1 or Bis. ${ }^{8-12}$ Here we report our recent findings attesting the expression and prosurvival activity of this protein in human primary leukaemic cells from patients affected by B-CLL. Our analyses were conducted on peripheral blood leukaemic cells from 29 patients affected by B-CLL; patients' profiles are reported in Table 1.

By RT-PCR (Figure 1, Aa) and immunoblotting (Figure 1, $\mathrm{Bb})$, we detected the expression of BAG3 gene in leukaemic cell samples from B-CLL-affected patients. To investigate whether BAG3 protein exerted a role in maintaining B-CLL cell survival and/or control the apoptotic response to therapy, a possible approach was to downmodulate BAG3 protein synthesis and verify the effect on B-CLL cell apoptosis. To this end, we used phosphorothioate oligodeoxynucleotides that can efficiently enter and combine with their target in human primary hematopoietic normal and neoplastic cells. ${ }^{7,15-16}$ Antisense (TGCATCATGGGCGAGTGGGTGGCGG, antisense 1; GCTCATGCTGGGTTGGGGTCTG, antisense 2; ATTAAAGGCGGGGGTGACGTGG, antisense 3) phosphorothioate oligodeoxynucleotides, specifically di- rected at BAG3- selective mRNA portions, ${ }^{10,12}$ and nonsense controls (TTATATTCTATTATATTTATGAACTCC, nonsense 1; CCTCGTAACCACCGACCTCAAT, nonsense 2; GCTTATGGAGGATTGAGGTTGG, nonsense 3) were constructed and administered to $B-C L L$ cells in vitro. In cultures added with medium alone or control oligonucleotides, BAG3 protein was clearly appreciable by intracellular immunofluorescence; the intensity of the fluorescence signal was markedly reduced by the effect of antisense oligonucleotides (Figure 1, Ba) which instead did not modify cell staining with a BAG1-specific antibody (Figure 1, Bb). Downregulation of BAG3 expression was observed in nine out of nine analysed samples (patient 2,5,6,7,12,17,25,26,27 of Table 1).

We then investigated whether BAG3-specific antisense oligonucleotides could affect cell apoptosis. In accord with

Table 1 Profiles of the analysed patients

\begin{tabular}{|c|c|c|c|c|c|}
\hline Patient no. & CD5 & $\begin{array}{l}\text { CD19/ } \\
\text { CD20 }\end{array}$ & $\begin{array}{c}\text { Leucocyte } \\
\times 10^{9} / \mathrm{L}\end{array}$ & $\begin{array}{c}\text { RAI/ } \\
\text { BINET }\end{array}$ & $\begin{array}{c}\text { Age } \\
\text { (y) }\end{array}$ \\
\hline 1 & + & + & 44.1 & $\mathrm{I} / \mathrm{A}$ & 56 \\
\hline 2 & + & + & 17.4 & $\mathrm{I} / \mathrm{A}$ & 66 \\
\hline 3 & + & + & 17.0 & IV/C & 80 \\
\hline 4 & & + & 18.8 & III/C & 62 \\
\hline 5 & + & + & 25.9 & II/B & 55 \\
\hline 6 & + & + & 35.9 & II/B & 53 \\
\hline 7 & - & + & 10.5 & $\mathrm{I} / \mathrm{A}$ & 76 \\
\hline 8 & + & + & 25.2 & $\mathrm{I} / \mathrm{A}$ & 45 \\
\hline 9 & + & + & 17.8 & IV/C & 82 \\
\hline 10 & + & + & 24.0 & II/B & 79 \\
\hline 11 & + & + & 59.5 & II/A & 58 \\
\hline 12 & + & + & 8.6 & $\mathrm{I} / \mathrm{A}$ & 75 \\
\hline 13 & + & + & 26.6 & IV/C & 53 \\
\hline 14 & - & + & 48.8 & II/B & 77 \\
\hline 15 & + & + & 12.0 & II/B & 68 \\
\hline 16 & + & + & 17.7 & $\mathrm{I} / \mathrm{A}$ & 67 \\
\hline 17 & + & + & 28.7 & IV/C & 78 \\
\hline 18 & + & + & 34.9 & IV/C & 74 \\
\hline 19 & + & + & 12.3 & II/B & 75 \\
\hline 20 & - & + & 5.6 & II/B & 45 \\
\hline 21 & + & + & 18.5 & II/B & 59 \\
\hline 22 & + & + & 46.1 & IV/C & 72 \\
\hline 23 & + & + & 53.4 & I/A & 73 \\
\hline 24 & + & + & 22.6 & $\mathrm{I} / \mathrm{A}$ & 73 \\
\hline 25 & + & + & 16.7 & $0 / A$ & 68 \\
\hline 26 & + & + & 14.8 & $0 / A$ & 73 \\
\hline 27 & + & + & 14.4 & II/B & 70 \\
\hline 28 & + & + & 89.1 & $\mathrm{I} / \mathrm{A}$ & 74 \\
\hline 29 & + & + & 20.2 & $0 / A$ & 76 \\
\hline
\end{tabular}


A

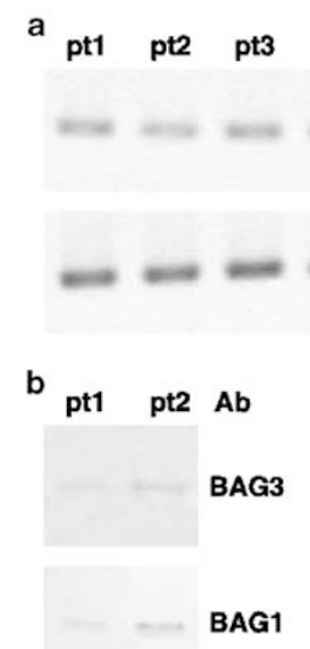

B
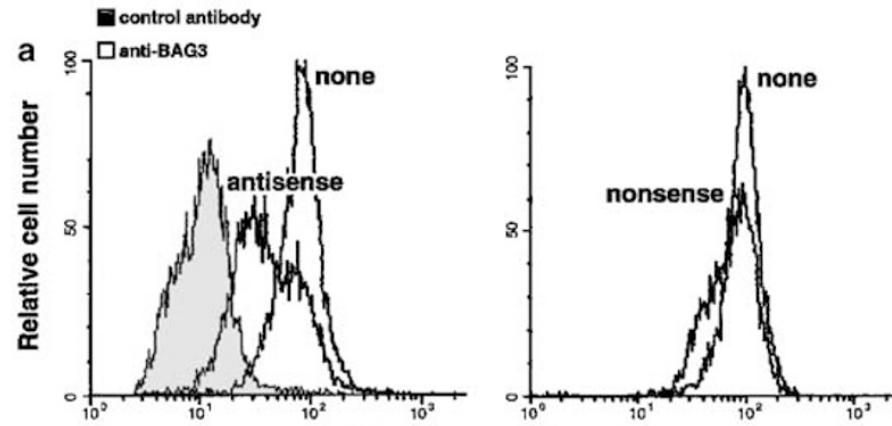

Fluorescence channel
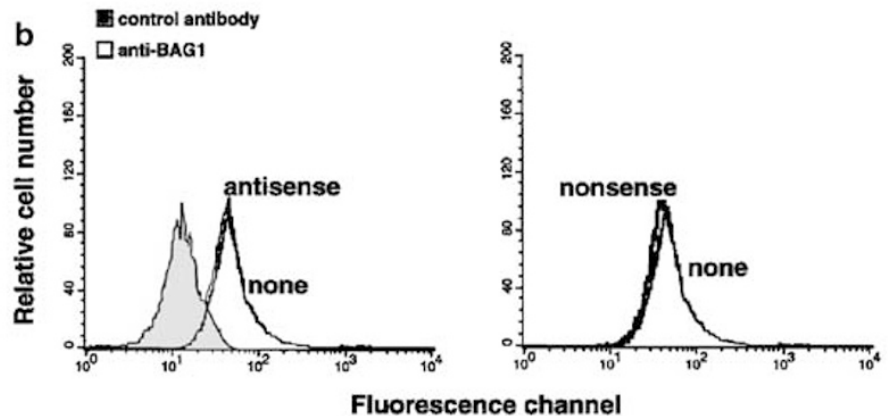

Fluorescence channel

C

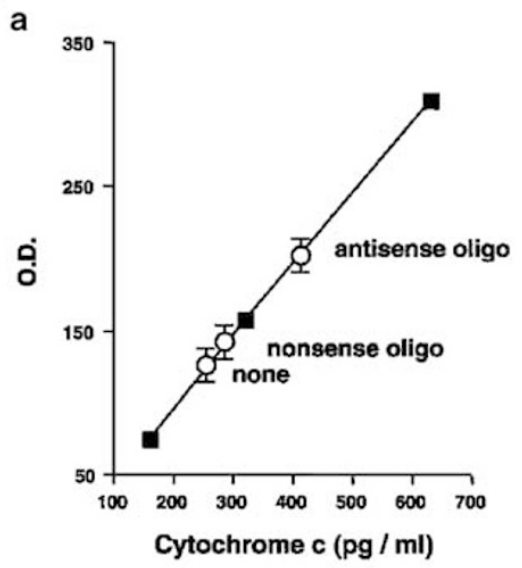

b

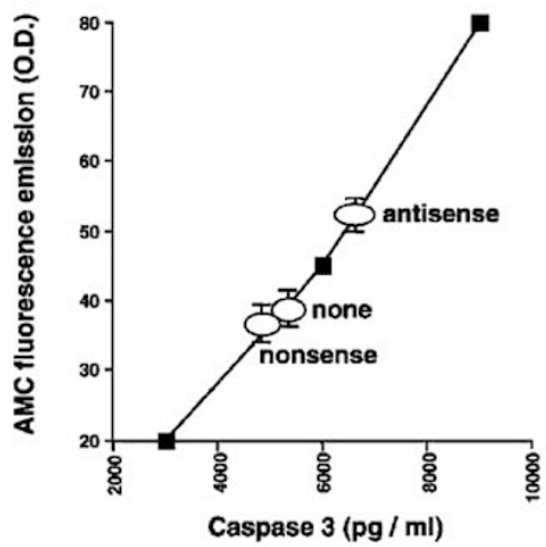

D

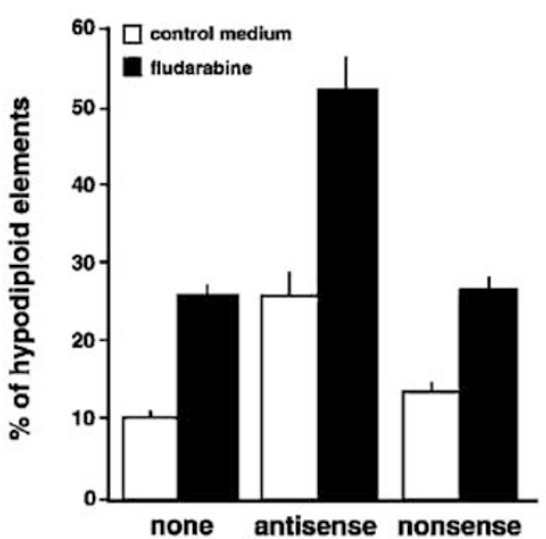

Figure 1 A-a: RNA was extracted from B-CLL cells $\left(50 \times 10^{6}\right)$ of four different patients ( $\left.p t\right)$ and subjected to PCR analysis with BAG3- or GAPDH-specific primers. b: Extracts from B-CLL cells were analysed by immunoblotting with an anti-BAG3 polyclonal raised against the $\mathrm{COOH}$ region of the protein (Pagliuca et al., submitted). The anti-BAG1 monoclonal antibody (mAb) KS-6C8 (DAKO Corp, Carpinteria, CA, USA) was used as a positive control. B - BAG3-antisense (TGCATCATGGGCGAGTGGGTGGCGG) or nonsense control (TTATATTCTATTATATTTATGAACTCC) phosphorothioate oligodeoxynucleotides (Primm Srl, Milan, Italy) (5 $\mu$ M) was added to B-CLL cell cultures for $20 \mathrm{~h}$; then, the cells were analysed by intracellular immunofluorescence with BAG3- (a) or BAG1- (b) specific antibodies. A pre immune rabbit antibody and the anti-Bcl-2 mAb SC-7382 (Santa Cruz Biotechnology, Santa Cruz, CA, USA) were used as negative and positive controls, respectively. Analogous results were obtained in experiments with nine different B-CLL samples (patient \# 2,5,6,7,12,17,25,26,27 of Table 1) and with any one of the three antisense (TGCATCATGGGCGAGTGGGTGGCGG, antisense 1; GCTCATGCTGGGTTGGGGTCTG, antisense 2; ATTAAAGGCGGGGGTGACGTGG, antisense 3), but not control (TTATATTCTATTATATTTATGAACTCC, nonsense 1; CCTCGTAACCACCGACCTCAAT, nonsense 2; GCTTATGGAGGATTGAGGTTGG, nonsense 3) oligonucleotides. C - B-CLL cells $\left(1 \times 10^{6} / \mathrm{ml}\right)$ were cultured in 10\% FCS-RPMI without or with control nonsense or BAG3-specific antisense oligonucleotides $(5 \mu \mathrm{M})$. Cytosolic lysates were obtained at 3 or $8 \mathrm{~h}$ and analysed for cytochrome $c$ content ${ }^{13}(\mathbf{a})$ or caspase- 3 activity ${ }^{14}(\mathbf{b})$, respectively. Results are representative of one of the three experiments with different B-CLL samples; analogous results were obtained in the other two. D - B-CLL cells $\left(1 \times 10^{6} / \mathrm{ml}\right)$ from 29 patients were cultured in $10 \%$ FCS-RPMI without or with fludarabine (9- $\beta$-D-arabinosyl-2-fluoroadenine-monophosphate, Schering Spa, Milan, Italy) ( $3 \mu \mathrm{g} / \mathrm{ml}$ ) and control nonsense or BAG3-specific antisense oligonucleotides $(5 \mu \mathrm{M})$. After 5 days, the percentages of hypodiploid nuclei were determined by propidium iodide ncorporation in permeabilised cells and flow cytometry. ${ }^{17}$

previously reported observations, indicating that B-CLL cells show a modest degree of spontaneous cell apoptosis following their culture in vitro, ${ }^{5,7}$ we could detect a spontaneous activation of two apoptosis-related events: mitochon- drial cytochrome $c$ release in cell cytosol (Figure 1, Ca) and caspase-3 activity (Figure 1, Cb), in B-CLL cell cultures. Such events appeared to be stimulated by the addition of BAG3downmodulating oligonucleotides: indeed, in B-CLL cells 
incubated with antisense oligodeoxynucleotides for 3 or $8 \mathrm{~h}$, there was a more than the $40 \%$ increase in both cytochrome $c$ release (Figure 1, Ca) and caspase-3 activity (Figure 1, Cb), respectively. Next, we analysed the effect of BAG3 antisense, alone or combined with the chemotherapeutic compound fludarabine, in the 29 samples of Table 1. Cells were cultured for 5 days without or with antisense or control nonsense oligonucleotides and/or fludarabine; the percentages of apoptosis, measured as hypodiploidy in flow cytometry, ${ }^{17}$ are shown in Figure 1, d panel. Cells incubated in control medium displayed the $10.1 \pm 1.3 \%$ (range: $2.7-18.2 \%$ ) of hypodiploid elements; a similar percentage $(12.2 \pm 1.3 \%$; range: $3.2-21.0 \%$ ) was detected in cultures with control nonsense oligodeoxynucleotides, while apoptosis reached the $25.0 \pm 3.3 \%$ (range: $10.3-37.1 \%$ ) in cultures with BAG3 antisense. Therefore in consequence of BAG3 downmodulation, the apoptosis percentages were raised by more than $100 \% \quad(P=0.0005)$. Furthermore, while fludarabine induced in cell cultures the $25.6 \pm 1.7 \%$ (range: $12.8-36.2 \%$ ) of apoptosis (similar to cultures with antisense oligo alone), this percentage was raised up to the $51.9 \pm 4.1 \%$ (range: 27.4-71.3) in cultures incubated with fludarabine and the antisense oligo. No appreciable variations were detected with the control nonsense oligo (26.2 $\pm 2.0 \%$; range: 13.4-38.9\%).

These findings indicate that, in addition to BAG1, 4,5 another member of the same protein family, BAG3, exerts a prosurvival activity in B-CLL cells. These pieces of evidence concur in identifying BAG proteins as relevant modulators of the survival/apoptosis balance in B-CLL. BAG proteins can counteract cell apoptosis by more than one mechanism. ${ }^{8}$ In this respect, they could exert a versatile, and therefore particularly effective, antiapoptotic activity, influencing different death pathways initiated by intracellular programmes or extracellular stimuli (immune attack, TNFR/CD95 ligands, chemotherapy). Functional interactions of BAG3 with $\mathrm{Hsp}^{18,19}$ and other possible partners ${ }^{8}$ are currently investigated in our laboratory.

Since downmodulation of BAG3 protein levels results in BCLL cell apoptosis, such protein appears to be required for cell survival in this type of tumour; consequently, hampering its expression and/or activity can result in an antineoplastic effect. BAG3 protein is also synthesised in normal B lymphocytes, where it can contrast oxidative stress-induced apoptosis (data not shown). Therefore, similar to $\mathrm{Bcl}-2$ or $\mathrm{Mcl}-$ $1,{ }^{20-22}$ it seems to display the same antiapoptotic property in normal as well as in leukaemia lymphocytes, where its activity results in sustaining the neoplastic process. More detailed analyses will clarify whether leukaemic cells harbour alterations in BAG3 protein levels and/or functioning. It should also be noted that BAG3 expression has been detected in other tissues, including skeletal muscle, heart, ovary. ${ }^{8}$ Its down- modulation in these cell types should clarify the tissue-specific role of BAG3 protein in cell survival. Finally, the expression and functional activity of BAG3 in normal human haematopoietic progenitors have not been analysed. These issues deserve investigation for a better understanding of mechanisms that control cell apoptosis in primary cells and a possible design of BAG3-based, leukaemia-specific therapies. ${ }^{23}$

\section{Acknowledgments}

We thank Mrs. Ornella Moltedo and Mr. Carmine Del Gaudio for their excellent technical assistance. Partially supported by funds from: Intramural grant University of Salerno, 60\% Funds; Associazione Italiana Ricerca sul Cancro (AIRC); Ministero dell'Istruzione e dell' Università (M.I.U.R.).

MF Romano 1 , M Festa ${ }^{2}$, G Pagliuca ${ }^{1,2}, R$ Lerose $^{2}, R$ Bisogni $^{1}$, F Chiurazzi $^{1}$, G Storti ${ }^{3}$, S Volpe ${ }^{3}, S$ Venuta $^{4}$, MC Turco ${ }^{\star, 3}$ and $A$ Leone ${ }^{2}$

${ }^{1}$ Dipartimento di Biochimica e Biotecnologie Mediche (DBBM) and Area di Ematologia (DACM), University of Naples "Federico II", Italy

2 Dipartimento di Scienze Farmaceutiche (DIFARMA), University of Salerno, Italy

${ }^{3}$ Servizio di Ematologia, Moscati Hospital, Avellino, Italy

4 Dipartimento di Medicina Sperimentale e Clinica (DMSC), University of Catanzaro "Magna Graecia", Italy

* Corresponding author: MC Turco, Dipartimento di Scienze Farmaceutiche (DIFARMA), University of Salerno, Via Ponte Don Melillo, 84084 Fisciano, Salerno, Italy; E-mail: mcturco@unisa.it

1. Reed J (1998) Clin. Immunol. Newslett. 17: 125-140.

2. Caligaris-Cappio $F(2000)$ Rev Clin Exp Hematol. 4:5-21.

3. Thomas A et al. (1996) Oncogene 12: 1055-1056

4. Kitada S et al. (1998) Blood 91: 3379-3389.

5. Kitada S et al. (2000) Blood 96:393-397.

6. Byrd JC et al. (2002) Blood 99:1038-1043.

7. Romano MF et al. (1998) Blood 92: 990-995.

8. Takayama $S$ et al. (2001) Nature Cell Biol. 3: 237-241.

9. Takayama S et al. (1999) J Biol Chem. 274:781-786.

10. Lee J-H et al. (1999) Oncogene 18: 6183-6190.

11. Doong $\mathrm{H}$ et al. (2000) Oncogene 19: $4385-4395$.

12. Antoku K et al. (2001) Biochem Biophys Res Comm. 286: 1003-1010.

13. Kluck RM et al. (1997) EMBO J 16: 4639-4649.

14. Nicholson DW et al. (1995) Nature 376: 37-39.

15. Romano MF et al. (1999) Blood 12: 4060-4066.

16. Romano MF et al. (2000) Gene Ther 7: 1234-1237.

17. Nicoletti I et al. (1991) J Immunol Methods 139:271-278.

18. Jaattela M (1999) Ann Med. 31: 261-265

19. Beere HM et al. (2001) Trends Cell Biol 11: 6-10.

20. Cory S. (1995) Annu Rev Immunol. 13: 513-543.

21. Lomo J et al. (1996) Cancer Res 56: 40-43.

22. Harris MH et al. (2000) Cell Death Differ 7: 1182-1191.

23. Bonzon C et al. (2002) Cell Death Differ 9: 780-782. 